\title{
Comparison of the myocardial protective effect of sevoflurane versus propofol in patients undergoing heart valve replacement surgery with cardiopulmonary bypass
}

Xiao-Lin Yang ${ }^{1 *}$, Dan Wang ${ }^{1}$, Guo-Yuan Zhang ${ }^{2}$ and Xiao-Lan Guo ${ }^{2}$

\begin{abstract}
Background: This study aimed to compare myocardial protective effects of anaesthesia with intravenous infusion of propofol versus inhalation of sevoflurane in patients undergoing heart valve replacement surgery with cardiopulmonary bypass.

Methods: Seventy-six patients undergoing valve replacement with cardiopulmonary bypass were randomly assigned to propofol or sevoflurane anesthesia during the surgery, respectively. For assessing myocardial injury, cardiac troponin I (CTnl) and creatine kinase isozyme (CK-MB) were determined before induction $\left(T_{0}\right), 0.5 \mathrm{~h}\left(\mathrm{~T}_{1}\right)$ and $3 \mathrm{~h}\left(\mathrm{~T}_{2}\right)$ after aortic unclamping, and $24 \mathrm{~h}\left(\mathrm{~T}_{3}\right)$ and $48 \mathrm{~h}\left(\mathrm{~T}_{4}\right)$ after surgery. The concentrations of interleukin (IL)- 6 and IL-10 as the systemic inflammatory and anti-inflammatory markers were also measured at above time points.

Results: In the sevoflurane group, the plasma concentrations of CTnI and CK-MB from $T_{1}$ to $T_{4}$ and the levels of IL- 6 and IL-10 from $T_{1}$ to $T_{2}$ were lower than those in the propofol group. Moreover, a higher ratio of automatic heart beat recovery and a shorter length of intensive care unit or hospital stay were found in the sevoflurane group comparing with the propofol group.
\end{abstract}

Conclusion: Sevoflurane anaesthesia produced more prominent myocardial protection and attenuated inflammatory response than propofol anaesthesia in patients with valve replacement surgery under cardiopulmonary bypass, resulting in shorter ICU and in-hospital stay.

Retrospective clinical trial registration: Identified as ChiCTR-IOR-16009979 at http://www.chictr.org.cn/.

Keywords: Myocardial protection, Cardiopulmonary bypass, Heart valve replacement, Sevoflurane, Propofol

\section{Background}

Cardiac surgical procedures unavoidably produce myocardial cell injury, which may originate from myocardial ischemia reperfusion, cardiopulmonary bypass (CPB), or operative procedure, etc. [1-5]. Previous studies suggested that both modern inhaled anesthetics (such as isoflurane or sevoflurane) and intravenous anesthetic

\footnotetext{
*Correspondence: yang_xl_yang@126.com

${ }^{1}$ Departments of Anaesthesiology, Affiliated Hospital of North Sichuan Medical College, 63\# Wenhua Road, Shunqing District, Nanchong, Sichuan 637000, People's Republic of China

Full list of author information is available at the end of the article
}

propofol have the effect of myocardial preservation in different degree [6-9]. Nevertheless, most of those studies were performed in patients undergoing coronary artery bypass grafting (CABG), while few studies in nonCABG patients. Furthermore, high quality meta-analyses in adult cases have showed controversial or contradicting results [10-15]. In this study, we compared the cardioprotective effect of anesthesia with intravenous propofol and inhaled sevoflurane in patients undergoing mitral, aortic or tricuspid valve replacement surgery. Plasma cardiac troponin-I (cTnI) and creatine kinase isozyme (CK-MB) were used as the primary markers of 
myocardial cell injury, and the levels of interleukin (IL)6 and IL-10 within $48 \mathrm{~h}$ after operation were used as the systemic inflammatory and anti-inflammatory markers.

\section{Methods}

\section{Experimental protocol}

This prospective, randomized control study was approved by our institutional ethics committee (Affiliated Hospital of North Sichuan Medical College, Nanchong, China). The written informed consents were obtained from 76 patients scheduled for open-heart cardiac surgery (univalve replacement of mitral, aortic or tricuspid valve due to stenosis or/and regurgitation) with cardiopulmonary bypass. All patients were American Society of Anaesthesiologists physical status II-IV, aged between 40 and 65 years, New York Heart Association classification of cardiac function II-III, ejection fraction greater than $40 \%$, no history of nervous system diseases. The patients were randomly assigned to the sevoflurane group or the propofol group with equal size according to computergenerated randomization. The sevoflurane group and the propofol group were anaesthetized by inhaled sevoflurane or by infusion of propofol during the entire operative procedure, respectively. Exclusion criteria included hypertensive disease, coronary artery disease, diabetes, chronic obstructive pulmonary disease, infective endocarditis, hematogenic and immune systemic disease, perioperative steroid therapy, and contraindications for using propofol or sevoflurane.

\section{Primary and secondary end-points}

The primary end-points were the changes of cTnI and CK-MB values from the beginning of anaesthesia to $48 \mathrm{~h}$ after operation. Secondary end-points included the changes of IL- 6 and IL-10 during and within $48 \mathrm{~h}$ after operation, the ratio of automatic heart beat recovery, the requirements of intraoperative vasoactive agents, and short-term clinical outcomes (time of mechanical ventilation, length of ICU/hospital stay, awareness during operation by postoperative following up, and serious complications or death).

\section{Perioperative management \\ Anaesthetic technique}

Patients were premedicated with intramuscular phenobarbital sodium $100 \mathrm{mg}$ and anisodamine $10 \mathrm{mg} 30 \mathrm{~min}$ preoperative. In the operating room, all patients were routinely monitored for the electrocardiogram, pulse oxygen saturation, end-tidal carbon dioxide pressure, invasive radial arterial pressure, central venous pressure and auditory evoked potential index (AEPi) with a PM9000 express multifunctional monitor (Mindray Medical International Limited, Shenzhen, China). Transesophageal echocardiograph and urine output were also monitored. In the two groups, anaesthesia was induced with midazolam $0.1-0.2 \mathrm{mg} \mathrm{kg}^{-1}$ and fentanyl $10 \mu \mathrm{g} \mathrm{kg}$ ${ }^{-1}$. Vecuronium $0.15 \mathrm{mg} \mathrm{kg}^{-1}$ was given to facilitate tracheal intubation. Mechanical ventilation was controlled using $100 \%$ oxygen with a tidal volume of $6-8 \mathrm{ml} \mathrm{kg}^{-1}$. A normal end tidal carbon dioxide pressure (35$45 \mathrm{mmHg}$ ) was obtained by adjusted the respiratory frequency at $12-16$ breaths/min. In the sevoflurane group, Anaesthesia was maintained by inhaled sevoflurane (1$5 \%)$, and fentanyl (5-10 $\mu \mathrm{g} \mathrm{kg} \mathrm{kg}^{-1}$ ) and vecuronium $0.1 \mathrm{mg} \mathrm{kg}{ }^{-1}$ boli as needed. During CPB, sevoflurane was administered through the oxygenator. The depth of anaesthesia before, during and after $\mathrm{CPB}$ was controlled at AEPi $30-40,15-30$ and $30-40$ by adjusted inhaled sevoflurane concentration, respectively [16-19]. In the propofol group, anaesthesia was maintained with propofol at a infusion rate of $3-10 \mathrm{mg} \cdot \mathrm{kg}^{-1} \cdot \mathrm{h}^{-1}$, and fentanyl (5-10 $\mathrm{gg} \mathrm{kg}^{-1}$ ) and vecuronium $0.1 \mathrm{mg} \mathrm{kg}^{-1}$ boli as needed; the depth of anaesthesia before, during and after CPB was also controlled at AEPi 30-40, 15-30 and 3040 by adjusted the infusion rate of propofol, respectively.

\section{Surgery and cardiopulmonary bypass}

The cold cardioplegia solution was prepared by magnesium sulfate $2.5 \mathrm{~g}$, potassium chloride $2 \mathrm{~g}$, and sodium bicarbonate $0.5 \mathrm{~g}$ in $500 \mathrm{ml}$ physiologic saline, and administered into the aortic root every $30 \mathrm{~min}$. The CPB procedure and surgical techniques under moderate hypothermia $\left(28-32{ }^{\circ} \mathrm{C}\right)$ were standardized. The two groups of patients were operated by the same group of cardiac surgeons. The CPB prime volume, 1000$1500 \mathrm{ml}$ calculated by patient's weight, contained lactate Ringer's solution, hetastarch, mannitol, heparin and blood (depending on the expected pump haematocrit). The perfusion pressure $(50-70 \mathrm{mmHg}$ ) was maintained by a continuous non-pulsatile blood-flow rate of 2.0$2.51 \mathrm{~min}^{-1} \mathrm{~m}^{-2}$ during CPB. All patients were weaned off $\mathrm{CPB}$ by the support of small doses of dopamine and norepinephrine. The patients were withdrawn from the study if the CPB time was less $30 \mathrm{~min}$ or over $120 \mathrm{~min}$ or repeated $\mathrm{CPB}$ was more than two times.

\section{Hemodynamic data}

Global hemodynamic data (mean arterial pressure [MAP], central venous pressure [CVP], cardiac output) were recorded just before the start of surgery, before the start of $\mathrm{CPB}$ (pre-CPB), 15 min after the end of $\mathrm{CPB}$, and at the end of the operation. Five consecutive beats were averaged.

\section{Intensive care unit management}

All patients were continuously supported by mechanical ventilation in the thoracic surgical intensive care unit (ICU) postoperatively. For analgesia and sedation, 
fentanyl 50-100 $\mu \mathrm{g}$ and midazolam $0.1 \mathrm{mg} \mathrm{kg}^{-1}$ were intravenous bolus according to clinical needs. Patients were extubated when they could maintain adequate spontaneous respiration and required minimal oxygen support. The amount of vasoactive drugs were recorded during operation and after admission to the ICU. Intraoperative awareness by operative questionnaire and the time of mechanical ventilation, as well as the length of ICU/hospital stay were documented.

\section{Laboratory measurements}

Blood samples $(4 \mathrm{ml})$ were collected from the peripheral or central venous line at just before induction $\left(\mathrm{T}_{0}\right)$, $30 \mathrm{~min}\left(\mathrm{~T}_{1}\right)$ and $3 \mathrm{~h}\left(\mathrm{~T}_{2}\right)$ after aortic unclamping, and $24 \mathrm{~h}\left(\mathrm{~T}_{3}\right)$ and $48 \mathrm{~h}\left(\mathrm{~T}_{4}\right)$ after operation. One $\mathrm{ml}$ of $4 \mathrm{ml}$ blood sample was used to measure the hematocrit (Hct), and the rest $3 \mathrm{ml}$ blood sample was used to measure the biomarkers of myocardial injury (cTnI, CK-MB), the inflammatory factor (IL-6) and anti-inflammatory factor (IL10) in our hospital clinical chemistry department. The concentrations of cTnI and CK-MB were determined by immunochemistry analytic method (reagent kit provided by Abbott Lab, US), and the lower detection limit is $0.01 \mathrm{ng} \mathrm{ml}^{-1}$. IL-6 and IL-10 were measured using enzyme-linked immunosorbent assay (reagent kit provided by Rapid Bio, USA), and the detection thresholds were $9 \mathrm{pg} \mathrm{ml}^{-1}$ and $15 \mathrm{pg} \mathrm{ml}^{-1}$, respectively. To avoid the effect of hemodilution on experiment data, the following formula was used to calibration: theoretical value $=$ measured value $\times$ (baseline Hct value/measured Hct value) . The baseline Hct was measured before induction.

\section{Statistical analysis}

A sample size of 70 cases would have a power of $95 \%$ to detect a difference in the level of cTnI of $2 \mathrm{ng} \mathrm{ml}^{-1}$ as a primary end-point using a two-sample $t$-test with 0.05 twosided significance level [11, 20, 21]. Patient characteristics were compared with an unpaired $t$ test and Fisher exact test where appropriate. Both biochemical serum markers and hemodynamic data were compared using a two-way analysis of variance techniques for repeated measurements in each group and between the two groups. All data were analyzed with the statistical package SPSS19.0 (SPSS Inc, Chicago, IL, USA) and expressed as mean (standard deviation) unless otherwise stated and statistical significance was accepted at $P<0.05$.

\section{Results}

The study included a total of 76 patients undergoing valve replacement surgery with $\mathrm{CPB}$. In the sevoflurane group, one patient was excluded from this study due to the $\mathrm{CPB}$ duration exceeding $120 \mathrm{~min}$. In the propofol group, two patients were excluded from this study because one case needed repetitive $\mathrm{CPB}$ and the other one's CPB duration exceeded $120 \mathrm{~min}$. The two groups were comparable with respect to sex, age, weight, types of surgery, $\mathrm{CPB}$ time, aortic clamp time, arrest time, total administered dose of fentanyl (midazolam), and the incidence of intraoperative awareness. However, compared with the propofol group, less consuming doses of vasoactive drugs, a higher ratio of automatic heart beat recovery, a shorter length of ICU or hospital stay were found in the sevoflurane group (Table 1). The changes

Table 1 Patient characteristics

\begin{tabular}{|c|c|c|}
\hline Patient characteristics & Propofol $(n=37)$ & Sevoflurane $(n=36)$ \\
\hline \multicolumn{3}{|l|}{ Preoperative data } \\
\hline Age (yr) & $50.7(6.6)$ & $50.5(6.4)$ \\
\hline Weight (kg) & $54.5(7.9)$ & $56.5(11.8)$ \\
\hline $\operatorname{Sex}(M / F)$ & $18 / 19$ & $16 / 20$ \\
\hline ASA class & $\|-I V$ & $\|-I V$ \\
\hline EF (\%) & $57.2(5.6)$ & $55.9(5.4)$ \\
\hline \multicolumn{3}{|l|}{ Types of surgery (n, \%) } \\
\hline Replacement of mitral valve & $15(40)$ & $14(39)$ \\
\hline Replacement of aortic valve & $9(24)$ & $10(28)$ \\
\hline Replacement of tricuspid valve & $4(10)$ & $4(11)$ \\
\hline $\begin{array}{l}\text { Replacement of mitral valve } \\
\text { and shaping of tricuspid valve }\end{array}$ & $9(24)$ & $8(22)$ \\
\hline \multicolumn{3}{|l|}{ Intraoperative data } \\
\hline Operating time (min) & $198(28)$ & $183(34)$ \\
\hline CPB time (min) & $95(18)$ & $96(17)$ \\
\hline Aortic clamp time (min) & $62(21)$ & $64(18)$ \\
\hline $\begin{array}{l}\text { Ratio of automatic heart } \\
\text { beat recovery (\%) }\end{array}$ & 62.2 & $83.3^{*}$ \\
\hline $\begin{array}{l}\text { Incidence of intraoperative } \\
\text { awareness (\%) }\end{array}$ & 0 & 0 \\
\hline Propofol (mg) & $857.3(166.5)$ & 0 \\
\hline Sevoflurane (MAC hour) & 0 & $4.6(0.9)$ \\
\hline Fentanyl (mg) & $2.0(0.2)$ & $2.1(0.3)$ \\
\hline Midazolam (mg) & $20.6(2.9)$ & $22.8(3.0)$ \\
\hline Dopamine (mg) & $57.3(13.5)$ & $45.9(15.1)^{*}$ \\
\hline Nitroglycerin $(\mu \mathrm{g})$ & $130.3(50.2)$ & $102.2(34.5)^{*}$ \\
\hline Epinephrine $(\mu \mathrm{g})$ & $148.7(37.8)$ & $111.6(19.6)^{*}$ \\
\hline \multicolumn{3}{|l|}{ Postoperative data } \\
\hline $\begin{array}{l}\text { Duration of mechanical } \\
\text { ventilation time (hr) }\end{array}$ & $9.4(1.5)$ & $6.2(0.8)^{*}$ \\
\hline $\begin{array}{l}\text { Serious complications } \\
\text { or death (\%) }\end{array}$ & 0 & 0 \\
\hline ICU stay (hr) & $48.6(3.7)$ & $42.3(3.5)^{*}$ \\
\hline Hospital stay (d) & $16(13-19)$ & $12(9-15)^{*}$ \\
\hline
\end{tabular}

Values are expressed as mean (SD) or median (range). ${ }^{*} P<0.05$ vs the value of propofol group

EF Ejection fraction, ASA class American Society of Anaesthesiologists physical status classification, MAC minimum alveolar concentration, MAC hr inhaled anaesthetic concentration/MAC $\times$ inhaled time $(\mathrm{hr})$ 
of AEPi in the two groups were kept similar (Fig. 1). Both mean arterial pressure and cardiac output after $\mathrm{CPB}$ were decreased in the propofol group but not in the sevoflurane group (Table 2). Central venous pressure was kept stable throughout in both groups. A similar trend of cTnI, CK-MB, IL- 6 or IL-10 in the two groups was observed: the biomarkers increased very fast $30 \mathrm{~min}$ after aortic unclamping and peaked $3 \mathrm{~h}$ later, then started to decrease gradually. CTnI and CK-MB remained increased even at $48 \mathrm{~h}$ after operation, while IL-6 and IL-10 returned to baseline levels. However, the respective levels in the sevoflurane group were always lower than those in the propofol group in corresponding time points (Table 3 ).

\section{Discussion}

Our study shows that patients receiving sevoflurane anaesthesia have better myocardial protective effect than patients receiving propofol anaesthesia for the heart valve replacement surgery under $\mathrm{CPB}$. In the present study, both the cTnI and CK-MB were used as the sensitive and specific indicators of myocardial cell injury [2225]. In order to meet the needs of a better comparability of cardioprotection between the two groups, a similar depth of anaesthesia was monitored by AEP index through adjusting the inhaled sevoflurane concentration or the infusion rate of propofol in different periods of surgical procedure (pre-, during and post-bypass) (Fig. 1), and the proportions of valve replacement in both groups are also similar (Table 1). Although surgical procedure itself - as heart valve replacement implicates direct myocardial injury and the leak of cTnI and CK-MB, a lower level of cTnI or CK-MB was found in the sevoflurane group. It implicates sevoflurane may alleviate the myocardial cell injury to some degree. Our present results are well coincident with previous studies by using inhaled anaesthetics in CABG or paediatric cardiac surgery $[1,2,4,20,26,27]$. Studies have reported that the cardioprotection mechanism of inhaled anesthetics such as, volatile anesthetics open intracellular $\mathrm{K}_{\mathrm{ATP}}$ channels, activate adenosine receptors, and inhibit $\mathrm{Na}^{+} / \mathrm{K}^{+}$pump [1, $8,28,29]$. Studies have also reported that the cardioprotection mechanism of propofol is related to its anti-inflammatory, immunomodulatory and antioxidant properties [21, 30, 31]. Nevertheless, many studies, such as some prospective randomized controlled trials $[10-13,32]$ and observational study [14] in adult patients indicated some contradicting results on the cardioprotection between volatile and non volatile agents. We speculate the reasons of these contradictory results may be related to the differences of patients' conditions, anaesthesia protocols, surgery types and procedures, etc. For example, volatile anaesthetics or propofol were administered in any combination of the pre-, during and post-bypass period in previous studies. In Bignami's study, no difference was found in the myocardial protective effect between sevoflurane and propofol [32], which may partly due to no administration of sevoflurane during $\mathrm{CPB}$ in the inhalation anesthesia group. On the contrary, in our present study, both sevoflurane and propofol were administered throughout the operative procedure, which may provide an optimal cardioprotection. In addition, the cardioprotective effect produced by sevoflurane or propofol may related to the concentration used in some degree. Laboratory investigations reported 1.0 MAC of volatile anaesthetics provides beneficial effect to cardiac injury. Lower concentrations of less than 0.75 MAC often showed no effect, whereas higher concentrations

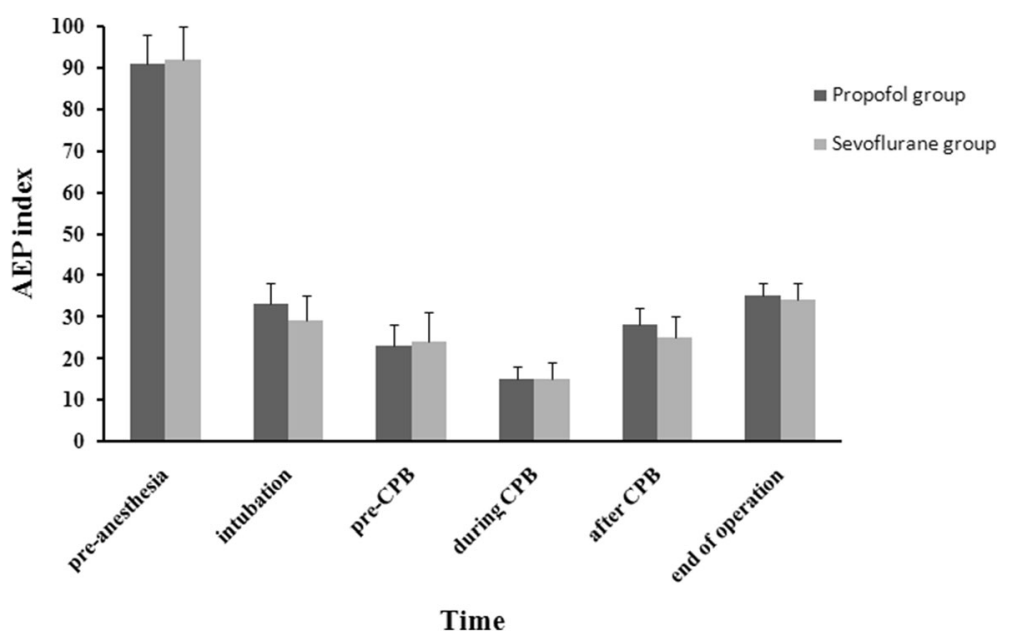

Fig. 1 The changes of auditory evoked potential index (AEPi) in the two groups. The changes of AEPi were kept similar in pre-anaesthesia, intubation, pre- $\mathrm{CPB}$, during $C P B$, after $\mathrm{CPB}$ and the end of operation between the two groups, respectively. $\mathrm{CPB}=$ Cardiopulmonary bypass 
Table 2 Perioperative Hemodynamic Data

\begin{tabular}{|c|c|c|c|c|}
\hline Parameter & Start of surgery & Pre-CPB & Post-CPB & End of surgery \\
\hline \multicolumn{5}{|l|}{ MAP (mmHg) } \\
\hline Propofol & $82(3)$ & $76(5)$ & $68(4)^{*}$ & $71(4)^{*}$ \\
\hline Sevoflurane & $79(4)$ & $77(5)$ & $76(3)^{\#}$ & $80(3)^{\#}$ \\
\hline \multicolumn{5}{|l|}{ CVP $(m m H g)$} \\
\hline Propofol & $11(3)$ & $12(2)$ & $11(3)$ & $12(3)$ \\
\hline Sevoflurane & $12(3)$ & $11(3)$ & $12(2)$ & $12(2)$ \\
\hline \multicolumn{5}{|c|}{ Cardiac output (I/min) } \\
\hline Propofol & $5.7(0.7)$ & $5.2(0.8)$ & $4.6(0.7)^{*}$ & $4.7(0.5)^{*}$ \\
\hline Sevoflurane & $5.5(0.8)$ & $5.4(0.9)$ & $5.6(0.6)^{\#}$ & $5.4(0.6)^{\#}$ \\
\hline
\end{tabular}

Data are mean (SD). * Different compared to before the start of surgery $(P<0.05)$. \# Different between propofol and sevoflurane $(P<0.05)$ MAPmean arterial pressure, CVP central venous pressure, $C P B$ cardiopulmonary bypass

of more than 1.5 MAC did not result in further protective effect $[1,33,34]$. In this study, AEPi was used to conduct the regulation of inhaled sevoflurane concentration or the infusion rate of propofol in different surgical procedures. No intraoperative awareness occurred in the two groups implied that the administered sevoflurane concentration (1-5\%) and the infusion rate of propofol $\left(3-8 \mathrm{mg} \mathrm{kg}^{-1} \mathrm{~h}^{-1}\right)$ were reasonable. However, the use of sevoflurane was associated with a significant increase in the ratio of automatic heart beat recovery after aorta unclamping, a more stable mean arterial pressure (Table 2) and a less inotropic support (Table 1) during operation. It indicated the depression of cardiac function in the sevoflurane group was less than that in the propofol group. In addition, that a significant reduction in the time of mechanical ventilation, length of ICU stay and the time to hospital discharge can make patients with valve replacement benefit from the use of sevoflurane throughout the entire procedure.

It is well-known that $\mathrm{CPB}$ and operative procedure often evoke a nonseptic systemic inflammatory reaction, with the potential risk of postoperative cardiac dysfunction $[29,30,35]$. The anti-inflammatory potential of sevoflurane has been reported in lots of CABG surgeries under $\mathrm{CPB}[36,37]$. When compared with the systemic delivery of sevoflurane, Kortekaas and co-authors in their study found that the intramyocardial delivery of sevoflurane can more strongly attenuate the systemic inflammatory response after CPB [38]. The results of this study also indicated sevoflurane possesses a strong property to depress the systemic inflammatory response in patients with valve replacement surgery. In this study, the lower plasma levels of prime proinflammatory cytokine IL-6 and anti-inflammatory cytokine IL-10 in the sevoflurane group during $48 \mathrm{~h}$ after surgery, indicates that sevoflurane anaesthesia attenuated postoperative cytokine response vs. propofol anaesthesia. This effect, on top of sevoflurane cardiac protective effect, may have independently contributed to the enhanced recovery of the patients.

Our study has several limitations. Firstly, although the patients could be randomly assigned to the sevoflurane group and the propofol group, the anaesthesiologists could not be blinded to the anaesthetic technique used in each group. However, the experimenters who collected the postoperative data and the laboratory staff were blinded to the randomization. Secondly, the data resulted from a relatively small number of patients. Therefore, more patients were needed for further study. Thirdly, in some degree, our present study lacked a clinically important positive outcome, which may due to a less myocardial ischemia or injury in non-CABG cases

Table 3 Perioperative markers of myocardial injury and systemic inflammation

\begin{tabular}{|c|c|c|c|c|c|}
\hline Marker & $\mathrm{T}_{0}$ & $\mathrm{~T}_{1}$ & $\mathrm{~T}_{2}$ & $\mathrm{~T}_{3}$ & $\mathrm{~T}_{4}$ \\
\hline \multicolumn{6}{|l|}{ cTnl (ng/ml) } \\
\hline Propofol & $0.01(0.02)$ & $18.26(9.67)^{\#}$ & $26.66(9.10)^{\#}$ & $13.71(6.14)^{\#}$ & $8.72(4.83)^{\#}$ \\
\hline Sevoflurane & $0.02(0.02)$ & $10.17(6.63)^{\#^{*}}$ & $15.17(8.73)^{\#^{*}}$ & $9.00(6.43)^{\#^{*}}$ & $4.62(3.40)^{\#^{*}}$ \\
\hline \multicolumn{6}{|l|}{ CK-MB (u/l) } \\
\hline Propofol & $0.87(0.50)$ & $47.73(9.30)^{\#}$ & $86.12(7.50)^{\#}$ & $31.79(6.29)^{\#}$ & $14.35(4.31)^{\#}$ \\
\hline Sevoflurane & $0.88(0.60)$ & $28.54(7.69)^{\# \#^{*}}$ & $61.29(8.80)^{\#^{*}}$ & $20.60(7.84)^{\#^{*}}$ & $8.28(2.16)^{\#^{*}}$ \\
\hline \multicolumn{6}{|l|}{ IL-6 (pg/ml) } \\
\hline Propofol & $15.86(4.45)$ & $36.89(6.71)^{\#}$ & $59.69(7.53)^{\#}$ & $25.80(6.15)^{\#}$ & $17.14(5.17)$ \\
\hline Sevoflurane & $13.91(5.00)$ & $27.87(7.83)^{\#^{*}}$ & $42.67(8.89)^{\#^{*}}$ & $22.64(6.92)^{\#}$ & $15.44(4.54)$ \\
\hline \multicolumn{6}{|l|}{ IL-10 (pg/ml) } \\
\hline Propofol & $19.07(4.75)$ & $56.72(8.36)^{\#}$ & $73.73(7.44)^{\#}$ & $28.35(6.90)^{\#}$ & $20.58(7.56)$ \\
\hline Sevoflurane & $16.79(4.74)$ & $38.24(7.90)^{\#^{*}}$ & $54.29(8.08)^{\#^{*}}$ & $23.70(6.51)^{\#}$ & $18.88(5.50)$ \\
\hline
\end{tabular}

Data are given as mean (SD). $T_{0}=$ before induction, $T_{1}=30 \mathrm{~min}$ after aortic unclamping, $\mathrm{T}_{2}=3 \mathrm{~h}$ after aortic unclamping, $\mathrm{T}_{3}=24 \mathrm{~h}$ after surgery, $\mathrm{T}_{4}=48 \mathrm{~h}$ after surgery. ${ }^{\# P}<0.01$ vs. $T_{0} ;{ }^{*} P<0.05$ vs. the corresponding value in the propofol group 
than that in CABG cases, or a effective myocardial protection either produced by sevoflurane or propofol. Another limitation was that a relatively short CPB time was selected. However, the cardioprotective effect of sevoflurane or propofol in those patients with multi-valve replacement or longer $\mathrm{CPB}$ time needs a further multi-center clinical study.

\section{Conclusions}

In conclusion, patients receiving sevoflurane for uni-valve replacement surgery under $\mathrm{CPB}$ had significantly lower postoperative release of CTnI or CK-MB, and lighter inflammatory response than patients receiving propofol for the same procedure. Our findings suggest the administration of inhaled sevoflurane throughout the entire procedure can produce more significant myocardial protection and resulted in shorter ICU and in-hospital stay which may have further economic implications than the intravenous infusion of propofol.

\section{Abbreviations}

AEPi: Auditory evoked potential index; ASA: American Society of Anaesthesiologists; CABG: Coronary artery bypass grafting; CPB: Cardiopulmonary bypass; CTnl: Cardiac troponin I; Hct: Hematocrit; ICU: Intensive care unit; IL: Interleukin

\section{Acknowledgements}

No.

\section{Funding}

This study was funded by the program of the Department of Education of Sichuan Province, Chengdu, China, grant no. 07SG004-001.

\section{Availability of data and materials}

The datasets during the current study available from the corresponding author: Xiao-Lin Yang, Email: yang_xl_yang@126.com

\section{Authors' contributions}

$X-L Y$ is the first author and corresponding author who designed and conducted the study, analyzed the data, reviewed the data analysis, wrote the manuscript, approved the final version of the manuscript, and is responsible for archiving the study files. DW is the first co-author who took part in the design of this study and all the clinical anaesthesia management, collected and analyzed the data, wrote the manuscript, approved the final version of the manuscript. G-YZ determined the blood samples, analyzed the data and approved the final version of the manuscript. X-LG analyzed the data, revised the manuscript, approved the final version of the manuscript.

\section{Competing interests}

The authors declare that they have no competing interests.

\section{Ethics approval and consent to participate}

This study was approved by the institutional ethics committee of Affiliated Hospital of North Sichuan Medical College, Nanchong, China. All written informed consents were obtained from participative patients.

\section{Author details}

${ }^{1}$ Departments of Anaesthesiology, Affiliated Hospital of North Sichuan Medical College, 63\# Wenhua Road, Shunqing District, Nanchong, Sichuan 637000, People's Republic of China. 'Laboratory Medicine, Affiliated Hospital of North Sichuan Medical College, Nanchong, Sichuan 637000, People's Republic of China.
Received: 30 August 2016 Accepted: 20 February 2017

Published online: 04 March 2017

\section{References}

1. Conzen PF, Fischer S, Detter C, Peter K. Sevoflurane provides greater protection of the myocardium than propofol in patients undergoing offpump coronary artery bypass surgery. Anesthesiology. 2003;99(4):826-33.

2. Belhomme D, Peynet J, Louzy M, Launay JM, Kitakaze M, Menasché P. Evidence for preconditioning by isoflurane in coronary artery bypass graft surgery. Circulation. 1999;19(suppl100):II340-4.

3. Penta De Peppo A, Polisca P, Tomai F, De Paulis R, Turani F, Zupancich E, Sommariva L, Pasqualetti $P$, Chiariello L. Recovery of LV contractility in man is enhanced by preischemic administration of enflurane. Ann Thorac Surg. 1999;68(1):112-8.

4. Haroun-Bizri S, Khoury SS, Chehab IR, Kassas CM, Baraka A. Does isoflurane optimize myocardial protection during cardiopulmonary bypass? J Cardiothorac Vasc Anesth. 2001;15(4):418-21.

5. Carden DL, Granger DN. Pathophysiology of ischaemia-reperfusion injury. J Pathol. 2000;190(3):255-66.

6. Kato R, Foëx P. Myocardial protection by anesthetic agents against ischemia-reperfusion injury: an update for anesthesiologists. Can J Anaesth. 2002:49(8):777-91

7. Zaugg M, Schaub MC, Foëx P. Myocardial injury and its prevention in the perioperative setting. Br J Anaesth. 2004;93(1):21-33.

8. Lin E, Symons JA. Volatile anaesthetic myocardial protection: a review of the current literature. HSR Proc Intensive Care Cardiovasc Anesth. 2010;2(2):105-9.

9. Landoni G, Fochi O, Bignami E, Calabrò MG, D’Arpa MC, Moizo E, Mizzi A, Pappalardo F, Morelli A, Zangrillo A. Cardiac protection by volatile anesthetics in non-cardiac surgery? A meta-analysis of randomized controlled studies on clinically relevant endpoints. HSR Proc Intensive Care Cardiovasc Anesth. 2009;1(4):34-43.

10. Julier K, da Silva R, Garcia C, Bestmann L, Frascarolo P, Zollinger A, Chassot PG, Schmid ER, Turina MI, von Segesser LK, Pasch T, Spahn DR, Zaugg M. Preconditioning by sevoflurane decreases biochemical markers for myocardial and renal dysfunction in coronary artery bypass graft surgery: a double-blinded, placebo-controlled, multicentre study. Anesthesiology. 2003;98(6):1315-27.

11. De Hert SG, Ten Broecke PW, Mertens E, Van Sommeren EW, De Blier IG, Stockman BA, Rodrigus IE. Sevoflurane but not propofol preserves myocardial function in coronary surgery patients. Anesthesiology. 2002; 97(1):42-9.

12. De Hert S, Vlasselaers D, Barbé R, Ory JP, Dekegel D, Donnadonni R, Demeere $J$, Mulier J, Wouters P. A comparison of volatile and non volatile agents for cardioprotection during on-pump coronary surgery. Anaesthesia. 2009:64(9):953-60.

13. Cromheecke S, Pepermans V, Hendrickx E, Lorsomradee S, Ten Broecke PW, Stockman BA, Rodrigus IE, De Hert SG. Cardioprotective properties of sevoflurane in patients undergoing aortic valve replacement with cardiopulmonary bypass. Anesth Analg. 2006;103(2):289-96.

14. Jakobsen CJ, Berg H, Hindsholm KB, Faddy N, Sloth E. The influence of propofol versus sevoflurane anesthesia on outcome in 10,535 cardiac surgical procedures. J Cardiothorac Vasc Anesth. 2007;21(5):664-71.

15. Suryaprakash S, Chakravarthy M, Muniraju G, Pandey S, Mitra S, Shivalingappa B, Chittiappa S, Krishnamoorthy J. Myocardial protection during off pump coronary artery bypass surgery: a comparison of inhalational anesthesia with sevoflurane or desflurane and total intravenous anesthesia. Ann Card Anaesth. 2013;16(1):4-8.

16. Doi M, Gajraj RJ. Effect of cardiopulmonary bypass and hypothermia on electroencepha-lographi variables. Anaesthesia. 1997:52(11):1048-55.

17. Absalom AR, Sutcliffe N, Kenny GN. Effects of the auditory stimuli of an auditory evoked potential system on levels of consciousness, and on the bispectral index. Br J Anaesth. 2001;87(5):778-80.

18. Kurita T, Doi M, Katoh T, Sano H, Sato S, Mantzaridis H, Kenny GN. Auditory evoked potential index predicts the depth of sedation and movement in response to skin incision during sevoflurane anesthesia. Anesthesiology. 2001:95(2):364-70

19. Drummond JC. Monitoring depth of anesthesia: with emphasis on the application of the bispectral Index and the middle latency auditory evoked response to the prevention of recall. Anesthesiology. 2000;93(3):876-82. 
20. Malagon I, Hogenbirk K, Van Pelt J, Bovill JG. Effect of three different anaesthetic agents on the postoperative production of cardiac troponin $\mathrm{T}$ in paediatric cardiac surgery. Br J Anaesth. 2005;94(6):805-9.

21. Bettex DA, Wanner PM, Bosshart M, Balmer C, Knirsch W, Dave H, Dillier C, Bürki C, Hug M, Seifert B, Spahn DR, Beck-Schimmer B. Role of sevoflurane in organ protection during cardiac surgery in children: a randomized controlled trial. Interact Cardiovasc Thorac Surg. 2015;20(2):157-65.

22. Maynard SJ, Menown IB, Adgey AA. Troponin T or troponin I as cardiac markers in ischaemic heart disease. Heart. 2000;83(4):371-3.

23. Knothe C, Boldt J, Dehne M, Zickmann B, Porsch S, Dapper F, Hempelmann G. Comparison of different prophylactic myocardium saving measures during heart surgery. Effects on perioperative troponin-T levels. J Cardiovasc Surg. 1996;37(4):367-75.

24. Takeda S, Nakanishi K, Ikezaki H, Kim C, Sakamoto A, Tanaka K, Ogawa R. Cardiac marker responses to coronary artery bypass graft surgery with cardiopulmonary bypass and aortic cross-clamping. J Cardiothorac Vasc Anesth. 2002;16(4):421-5.

25. Borges FK, Furtado MV, Rossini AP, Bertoluci C, Gonzalez VL, Bertoldi EG, Pezzali LG, Machado DL, Grutcki DM, Rech LG, Magalhães M, Polanczyk CA. Clinical use of ultrasensitive cardiac troponin I assay in intermediate- and high-risk surgery patients. Dis Markers. 2013;35(6):945-53.

26. Likhvantsev W, Landoni G, Levikov DI, Grebenchikov OA, Skripkin YV, Cherpakov RA. Sevoflurane versus total intravenous anesthesia for isolated coronary artery bypass surgery with cardiopulmonary bypass: a randomized trial. J Cardiothorac Vasc Anesth. 2016;30(5):1221-7.

27. Li F, Yuan Y. Meta-analysis of the cardioprotective effect of sevoflurane versus propofol during cardiac surgery. BMC Anesthesiol. 2015;15:128. doi: 10.1186/s12871-015-0107-8.

28. Zaugg M, Lucchinetti E, Spahn DR, Pasch T, Schaub MC. Volatile anesthetics mimic cardiac preconditioning by priming the activation of mitochondrial KATP channels via multiple signaling pathways. Anesthesiology. 2002;97(1): 4-14.

29. Mathur S, Karmazyn M. Interaction between anesthetics and the sodium hydrogen exchange inhibitor HOE 642 (cariporide) in ischemic and reperfused rat hearts. Anesthesiology. 1997;87(6):1460-9.

30. An K, Shu H, Huang W, Huang X, Xu M, Yang L, Xu K, Wang C. Effects of propofol on pulmonary inflammatory response and dysfunction induced by cardiopulmonary bypass. Anaesthesia. 2008;63(11):1187-92.

31. Sayin MM, Özatamer O, Taşöz R, Kiling K, Unal N. Propofol attenuates myocardial lipid peroxidation during coronary artery bypass grafting surgery. Br J Anaesth. 2002;89(2):242-6.

32. Bignami E, Landoni G, Gerli C, Testa V, Mizzi A, Fano G, Nuzzi M, Franco A, Zangrillo A. Sevoflurane vs. propofol in patients with coronary disease undergoing mitral surgery: a randomised study. Acta Anaesthesiol Scand. 2012;56(4):482-90.

33. Wang J, Zheng H, Chen CL, Lu W, Zhang YQ. Sevoflurane at 1 MAC provides optimal myocardial protection during off-pump CABG. Scand Cardiovasc J. 2013:47(3):175-84

34. Obal D, Preckel B, Scharbatke H, Müllenheim J, Höterkes F, Thämer V, Schlack W. One MAC of sevoflurane provides protection against reperfusion injury in the rat heart in vivo. Br J Anaesth. 2001;87(6):905-11.

35. Kawamura T, Wakusawa R, Okada K, Inada S. Elevation of cytokines during open heart surgery with cardiopulmonary bypass: participation of interleukin 8 and 6 in reperfusion injury. Can J Anaesth. 1993;40(11):1016-21.

36. De Hert SG, Van der Linden PJ, Cromheecke S, Meeus R, Nelis A, Van Reeth V, ten Broecke PW, De Blier IG, Stockman BA, Rodrigus IE. Cardioprotective properties of sevoflurane in patients undergoing coronary surgery with cardiopulmonary bypass are related to the modalities of its administration. Anesthesiology. 2004;101(2):299-310.

37. Garcia C, Julier K, Bestmann L, Zollinger A, von Segesser LK, Pasch T, Spahn DR, Zaugg M. Preconditioning with sevoflurane decreases PECAM-1 expression and improves one-year cardiovascular outcome in coronary artery bypass graft surgery. Br J Anaesth. 2005;94(2):159-65.

38. Kortekaas KA, van der Baan A, Aarts LP, Palmen M, Cobbaert CM, Verhagen JC, Engbers FH, Klautz RJ, Lindeman JH. Cardiospecific sevoflurane treatment quenches inflammation but does not attenuate myocardial cell damage markers: a proof-of-concept study in patients undergoing mitral valve repair. Br J Anaesth. 2014;112(6):1005-14. 